\title{
Democracia y derechos humanos: compensación por la pérdida del juicio común en la era del capitalismo privado*
}

\section{Democracy and Human Rights: Compensation for the Loss of Collective Judgment in the Age of Private Capitalism}

\author{
Juan Carlos Quintero Calvache***
}

Recibido: 23 de mayo de 2016

Aprobado: 28 de noviembre de 2016

Disponible en línea: 30 de enero de 2017

\section{Resumen}

Este trabajo advierte que los imaginarios institucionales de la democracia representativa despojan a los individuos de la facultad de juzgar en común las situaciones del mundo que comparten en un espacio común, estableciendo universales que reemplazan el juicio individual y colectivo, para decidir y juzgar por anticipado, en nombre de los individuos, los eventos del mundo social. A partir de ahí, se logra evidenciar que la democracia funciona como un extraórgano que compensa la pérdida de la facultad de juzgar, y realiza los juicios y los deseos de los agentes sociales que viven un mundo común juzgado anticipadamente por un superpoder que emerge

\section{Abstract}

This work warns that the institutional imaginaries of representative democracy deprive individuals of the power to judge in common the situations of the world they share in a common space, establishing universals that replace individual and collective judgment, in order to decide and judge in advance, in the name of individuals, the events of the social world from there, it is possible to demonstrate that democracy functions as an extra-organ that compensates for the loss of the power to judge, and performs the judgments and desires of the social agents who live a common world judged in advance by a super power that emerges from

doi:10.11144/Javeriana.papo22-1.ddhc

* Artículo de investigación. Este artículo es un avance del proyecto de investigación La ley de verdad como principio de legitimidad de las instituciones políticas y de las normas.

** Abogado por la Universidad Libre de Colombia, licenciado en Filosofía por la Universidad del Valle, especialista en Derecho Penal y Criminología por la Universidad Libre de Colombia, magíster en Filosofía por la Universidad del Valle, doctor en Humanidades por la Universidad del Valle y posdoctor en Filosofía por la Université Paris 8. Profesor del Departamento de Humanidades de la Universidad Santiago de Cali. Correo electrónico: juancaquin@ gmail.com Orcid: http://orcid.org/0000-0003-4254-6207 
del modelo económico capitalista-liberal y de la mundialización económica y política. Se recurre a la antropología filosófica y a la teoría de la compensación para revelar que el capitalismo liberal adopta la democracia representativa como un modelo político que le permite asumir la orientación de la vida del individuo, sin apelar a la fuerza para arrebatarle su facultad de juzgar y decidir sobre su mundo. Se pudo determinar que la democracia y los derechos fundamentales cumplen la función instrumental de compensar en el individuo la pérdida de autonomía para juzgar en común el mundo social y político en la era de la mundialización. Desde ahí se puede comprender el alcance de la democracia y los derechos fundamentales cuando ambos resultan incompatibles con los propósitos capitalistas.

\section{Palabras clave:}

juicio en común; democracia; liberalismo; compensación; consenso

\footnotetext{
Cómo citar este artículo:

Quintero-Calvache, J. C. (2017). Democracia y derechos humanos: compensación por la pérdida del juicio común en la era del capitalismo privado. Papel Político, 22(1), 35-58. https:// doi.org/10.11144/Javeriana.papo22-1.ddhc
}

the capitalist-liberal economic model and from economic and political globalization. The article resorts to philosophical anthropology and compensation to reveal that liberal capitalism adopts representative democracy as a political model that allows it to assume the orientation of the individual's life, without appealing to the force to rob him of his faculty of judging and deciding on his world. It was possible to determine that democracy and fundamental rights fulfill the instrumental function of compensating in the individual the loss of autonomy to judge in common the social and political world in the era of globalization. From there, one can understand the scope of democracy and fundamental rights when both are incompatible with capitalist purposes.

\section{Keywords:}

collective judgment; democracy; liberalism; compensation; consensus 


\section{Introducción}

Retomar el concepto de democracia desde una perspectiva menos metafísica y más real puede implicar una incompatibilidad con la propia realidad que el concepto representa, especialmente cuando su propia existencia se funda en imaginarios sociales complejos que contienen, por una parte, una alta carga de principios y valores religiosos, y por otra, una alta carga de principios liberales económicos que van a justificar la asimetría de un poder político controlado por minorías que son, en últimas, la que controlan el capital económico.

El hecho de que la democracia como forma de ejercicio del poder político funcione controladamente en Occidente no significa que haya abandonado su condición de imaginario social; es más, esa condición es la que le permite proveerse de todas las justificaciones para hacer posible el proyecto no emancipador de las grandes colectividades, de mantener, precisamente bajo esos imaginarios, el control de las mayorías que aún consideran la democracia como el camino hacia la salvación, hacia la felicidad, hacia la condición de bienestar.

El neoplatonismo del siglo III d. C. contiene el fundamento de la idea del individualismo, en la que se funda la democracia real, o si se quiere en términos habermasianos, la democracia liberal. En la concepción neoplatónica, se deshace la idea etérea del alma humana para convertirla en materia, cambia completamente la perspectiva de la vida social, y señala al hombre como el único responsable de su salvación, salvación que se logra individualmente, condicionada al ejercicio de ciertas virtudes morales y cívicas; las virtudes intelectuales y la plegaria de devoción mística, así el individuo puede lograr la libertad del cuerpo y la unión con Dios. (Radhakrishnan y Raju, 1964).

En ese orden de ideas, la democracia salva al hombre y a sus dioses. Por un lado, la salvación del hombre no estará más en la potestad de terceros, sino en su propia potestad, abandonará toda forma teológica o religiosa, sin abandonar, eso sí, los principios religiosos que la fundamentan; por otro lado, asume la salvación de Dios ante todos los cuestionamientos por las desgracias humanas, justifica los fracasos sociales teniendo como único responsable al individuo y su grupo y permite reconocer las facultades autónomas y autodeterminadoras del individuo que lo separan completamente de Dios. Dicho de otra manera, la democracia es la teodicea de la política, y la salvación del hombre por el propio hombre.

Ahora le corresponde al hombre asumir sus propias responsabilidades, orientar por sí mismo su vida y definir la manera como resolverá los problemas que le devienen de su condición de animal carente. La imposibilidad de ser sí mismo sin otro lo ubica en un contexto social en el que está obligado a compartir con otros los ámbitos de la vida pública y las necesidades que resultan del ámbito privado. Resolver esos problemas implica una renuncia al ejercicio de la autodeterminación en casi todos los órdenes, y se ve obligado a transferir a otros la posibilidad de resolver por sí mismo los problemas que constantemente debe solucionar. 
En este artículo, se pretende mostrar que la democracia resulta ser una noción de compensación que deviene del superpoder que emerge del modelo económico capitalistaliberal y de la mundialización política y económica; una compensación de derechos por miserias económicas; una compensación de participación política por control de la vida pública y privada. La democracia compensa desigualdades sociales y económicas por libertades, derechos e igualdades políticas y jurídicas.

El argumento del trabajo se abordará desde dos perspectivas: 1) la filosofía antropobiológica de Arnold Gehlen 2) y la teoría de la compensación de Odo Marquard. A partir de Gehlen, se mostrará la base antropobiológica del modelo democrático participativo, para evidenciar, desde ahí, la manera como los individuos renuncian a la orientación de sus vidas y al juicio del estado de cosas cuando transfieren a las instituciones la solución de los problemas que le presenta el mundo cultural; luego, desde Marquard, se mostrará que el modelo democrático de representación política funciona como la teodicea del capitalismo liberal que le entrega al hombre la posibilidad de gobernar su mundo y su vida de manera autónoma sin la intervención de Dios, para hacer del hombre el único responsable de los desastres de su vida, compensado la muerte del tercero sagrado con el modelo de democracia representativa.

\section{La antropobiológica de la democracia}

La idea del capitalismo liberal es la de conceder a las mayorías algunas prebendas, como las libertades individuales y la participación para elegir gobernantes, que no son más que reafirmaciones de las diferencias y las desigualdades (Uexküll, 1957), mientras las minorías se reservan el control del mundo a partir del capital económico. De hecho, la idea contemporánea de democracia concibe la existencia de un modelo impuesto por el capital corporativo, una democracia impuesta que sabe muy bien que las mayorías "no podrán tener el control del mundo, pero tienen libertades y participación para elegir sus gobernantes" (Wolin, 2008, p. 259).

Sin embargo, el otorgamiento de tales prebendas no garantiza la autonomía y la autodeterminación de esas mayorías, la definición de los intereses y las necesidades no brota del ejercicio deliberativo, de los argumentos y razones de los individuos capaces de lenguaje y acción. Las necesidades y los intereses se definen en otros escenarios, en espacios donde el consenso de los mejores argumentos posibles se cubre de legitimidad positiva gracias a las instituciones burocráticas que definen lo que los individuos necesitan y no necesitan, lo que deben y no deben reclamar de sus instituciones. Instituciones que juzgan por el individuo y definen anticipadamente sus intereses, necesidades y razones.

Los estudios de anatomía comparada realizados hacia principios del siglo XX por el médico y antropólogo holandés Louis Bolk (2007) muestran la imperiosa necesidad que tiene el hombre de acudir a sus capacidades cognitivas para resolver el problema 
de su falta de especialidad biológica para enfrentar el mundo y construir su entorno. Su condición biológica lo pone en desventaja frente a mamíferos superiores que viven y se desarrollan en entornos específicos. El hombre como un animal desprovisto de elementos biológicos para la defensa, la caza, el clima, la naturaleza, e incluso desprovisto de instintos, tendrá que apelar a la acción para resolver los problemas que le genera su infraespecialidad biológica (Gehlen, 1987).

La condición de animal carente (Bolk, 2007) hace del hombre un animal sin entorno, un ser biológico no adaptado a la naturaleza y a las condiciones específicas que el medio natural ofrece. Sin embargo, su infraespecialidad biológica lo hace un ser abierto al mundo, completamente cargado por la necesidad permanente de resolver los problemas que le plantea el entorno que habita, que gracias a su plasticidad y a su capacidad de acción puede crear su propio mundo para enfrentar su desventaja biológica.

En igual proporción a la carga derivada de la infraespecialidad, el animal humano tiene que vérselas con la carga pulsional que se deriva de dos factores que para Gehlen tienen que ver con la falta de instintos animales y el exceso de estímulos que le vienen del mundo exterior. Esto sucede porque el hombre como un animal inacabado, un ser en estado larvario o neoténico, solo posee coordinación de sus funciones en el nivel intraespecífico, es decir que responde a necesidades de nutrición, reproducción, sexo y defensa, mientras que en el nivel extraespecífico no cuenta con mecanismos de inhibición de las acciones y, en su lugar, el sistema fonoauditivo de emisión y recepción reemplaza el sistema de instintos ausente en él.

El sistema fonoauditivo de emisión-recepción le permite al hombre resolver el exceso pulsional y atender la infinidad de estímulos que le vienen del mundo, porque a través él la biología humana logra reemplazar el sistema de instintos que falta en el hombre, para que este pueda responder solo a un estímulo concreto de entre la multiplicidad de estímulos que le vienen del mundo, y realizar una sola acción en respuesta a ese estímulo, de tal manera que

el uso de las correlaciones fonoauditivas en el entorno puede organizar las experiencias sensoriales del hombre, coordinando el uso del ojo con el uso de la mano, subordinando el aparato motor con el aparato receptor de la visión; y subordinando igualmente, el uso de los aparatos sensoriomotores con el uso de la palabra. (Poulain, 2003, p. 127)

Así, el lenguaje que fluye del funcionamiento del sistema fonoauditivo será para el hombre su medio de descarga, entre otras cosas, porque libera su cuerpo de la necesidad de ponerse en contacto permanente con las cosas para poder saber de ellas, más cuando el conocimiento de ellas y los eventos son condición necesaria para la solución de los problemas que tiene que afrontar el hombre tanto en su mundo natural cultural como en el mundo biológico altamente especializado. 
El lenguaje será para Gehlen la institución por excelencia que tendrá el hombre para crear cultura ${ }^{1}$ y resolver los problemas que le vienen por la carencia de instintos (1987, p. 43). Así, mientras cumple la función de reemplazar los instintos, el lenguaje funciona como mecanismo de descarga y orientación. La función de descarga permite que el hombre se libere a través del lenguaje de todas las presiones pulsionales y emocionales; y la función de orientación que cumple el lenguaje le permite identificar, de toda la multiplicidad de estímulos que recibe del mundo exterior, cuál es el que debe atender conforme a sus necesidades. Cada acción que realice responderá a una necesidad particular.

El hombre crea instituciones, para, a través de ellas, liberarse de la carga de respuestas que tiene que dar a las situaciones que se le presentan en su mundo natural cultural. Así, las instituciones aparecen, por un lado, como las formas de atender las tareas que representan importancia vital para él; y por otro, como los poderes estabilizadores que le proporcionan seguridad y firmeza a un ser que, por sus indigencias biológicas, es inseguro e inestable por naturaleza (Gehlen, 1993, p. 89).

De hecho, la política como una forma de relación y de acción entre el individuo y las instituciones burocráticas representa esa creación necesaria para la estabilidad del hombre que define acciones y no acciones. Esto significa que el modelo de democracia representativa para la orientación de la política constituye un instrumento estabilizador de la vida interior del hombre por medio del cual se descarga de la solución de múltiples problemas que se le presentan en su vida pública y privada.

Así, el hombre le transfiere a la democracia representativa la potestad de resolver en nombre de los individuos los problemas derivados de su relación con su mundo natural (la cultura) y con el mundo biológico cuando se trata de enfrentar los desafíos y las dificultades que este le plantea. Esa transferencia no es un simple acto de delegación para la toma de decisiones fundamentales en su vida cultural, sino que implica una pérdida de la facultad dispositiva para juzgar el estado de cosas y las situaciones del mundo cultural, y las respuestas a los desafíos del mundo biológico. La transferencia, en este caso, sustituye el juicio de los individuos y los somete al juicio de las instituciones; son ellas las que van a pensar y a juzgar en nombre de la democracia y en sustitución del hombre. Sin embargo, esa pérdida es compensada por la seguridad de que los juicios y las decisiones de terceros vienen garantizados por instituciones que resuelven los problemas vitales y reafirman la vida del hombre. Una especie de dios humano que todo lo puede y todo lo hace en nombre del hombre.

\footnotetext{
${ }^{1}$ La cultura entendida en términos de Gehlen como la capacidad del hombre para transformar las cosas del mundo en elementos que le permitan resolver los problemas generados por su falta de especialidad biológica para vivir en un entorno determinado. Por ejemplo, la creación de una herramienta para cortar o perforar es una creación cultural del hombre, a la vez que representa una extensión de su cuerpo que opera como instrumento de caza o de defensa, y en ese mismo orden, muchas de las herramientas creadas por el hombre, y la transformación de las condiciones del entorno y sus cosas, forman cultura, a la vez que resuelve las carencias biológicas que tiene que afrontar el animal humano.
} 
Así, las instituciones resultan tan necesarias para el hombre como su capacidad de acción, y está tan atado a ellas que cualquier intento de destrucción implica un estado de inseguridad y de inestabilidad en él, y de "carencia de protección frente a los estímulos por parte del comportamiento, que ahora sí se podría calificar de pulsional" (Gehlen, 1993, p. 91).

La democracia representativa se afianza en las condiciones antropobiológicas del hombre y aprovecha especialmente el exceso de estímulos del entorno que recibe y la sobrecarga de este respecto de la solución de problemas, para asumir la condición de un extraórgano humano capaz de pensar, juzgar, decidir y resolver en nombre de los individuos, y así descargarlo de la obligación constante de tener que resolver en todo momento y a toda hora situaciones de su entorno.

Cuando se afirma que la democracia representativa aprovecha las condiciones carenciales del animal humano, es porque, en razón de su inseguridad y falta de estabilidad, ofrece la posibilidad de que un tercero, que se presume representa sus intereses y necesidades, atienda todo cuanto le sea necesario para asegurar su existencia y permanencia en el entorno cultural.

Así como cada animal no humano tiene su estructura biológica adaptada específicamente para cada entorno natural de acuerdo con sus necesidades vitales, el modelo de democracia representativa se adapta al mundo perceptivo del animal humano y le ofrece la posibilidad de acondicionar un mundo natural cultural en el que pueda resolver sus necesidades vitales y, a la vez, sus intereses individuales y colectivos.

La inestabilidad e inseguridad en la que se halla el animal humano serán resueltas por "el contrato de concesión" político-burocrático que propone el modelo de democracia representativa. En ese "contrato", se le garantiza que las decisiones que tomen los contratistas en nombre de los contratantes representan los intereses y las necesidades de los últimos, es decir, de quienes en un proceso de elección son designados para asumir el papel de órgano reflexivo del cuerpo social.

De igual manera, el "contrato de concesión" que ofrece el modelo de democracia representativa eleva al más alto nivel la voluntad de los individuos y los sustrae del vínculo religioso que ata sus decisiones a la voluntad del tercero sagrado, para reconocerlos como agentes autónomos con capacidad para autodeterminarse, rompiendo el vínculo entre las deidades religiosas que definen la voluntad del individuo, para elevarlo al estatuto político, en el que se las tiene que ver solo con sus pares y no con algún tipo de deidad. Es un agente autónomo, cuyas decisiones derivadas de su voluntad no pasarán por el filtro de terceros.

Sin embargo, esa autonomía y autodeterminación quedan traslapadas en los procedimientos que el modelo representativo aplica para la designación de los terceros que van a operar las instituciones burocráticas. La autonomía política de los individuos llega hasta las fronteras que separan el asentimiento en las urnas por un representante 
burocrático y el escenario de las decisiones políticas de fondo. Los electores quedan atrapados en los límites de la opinión, de una opinión sin potencia de decisión y facultada simplemente para decir sí o para decir no.

La descarga del individuo en las instituciones vendrá a ser, para el modelo democrático y para quienes lo controlan, la mejor oportunidad que puede ofrecer ese animal carente para renunciar a su autocontrol y, con ello, transferir su razonabilidad y su capacidad argumentativa a terceros institucionales.

La vida política de los individuos cae en el autismo colectivo y el juicio de los individuos se neutraliza, con el aliciente de elegir los representantes en las instituciones burocráticas. La satanización de los juicios colectivos como elementos de perturbación del statu quo los hace responsables de las desgracias sociales (Poulain, 2003, p. 179) $\mathrm{y}$, en consecuencia, esos juicios tienen que ser ubicados en instancias instituciones que garanticen la no reproducción de las desgracias colectivas.

Si bien la democracia representativa confiere a los individuos la posibilidad de elegir entre un abanico de representantes que asumirán la dirección de las instituciones burocráticas, también se concentra en inhibir a los individuos para que se impida hablar en procura de penetrar en el espacio de la vida social, que hace de la experimentación discursiva en el plano político una completa desgracia.

Esta desgracia propia, en su momento, del capitalismo estatal soviético, del nacionalsocialismo y de los nacionalismos del este de Europa, se reproduce en los Estados del capitalismo liberal, aun cuando este se proponga salvar el juicio de los individuos haciendo que estos se identifiquen con el juicio colectivo que fluye de las instituciones burocráticas para alcanzar la meta política suprema que consiste en la unión de todos en el plano político (Poulain, 2003, p. 180).

Se procura, entonces, que el individuo adhiera sus deseos al deseo del consenso, a eso que de antemano ya es racional en la relación política, para que una vez adherido a ello se alcance el bien común concebido como la emancipación del individuo (Poulain, 2003). Esta propuesta pragmática de la democracia representativa se impone a otros escenarios políticos o a otros escenarios "ignorando las experiencias y las discusiones oriundas de los países del Sur en el debate sobre la democracia” (Avritzer y De Sousa Santos, 2003).

\section{La democracia representativa como teodicea ${ }^{2}$ del capitalismo liberal}

La condición de indigencia biológica que hace al animal humano un ser carencial que sobrevive gracias a su capacidad de acción y de lenguaje lo convierten, igualmente, en

\footnotetext{
${ }^{2}$ El término fue acuñado por Leibniz en su escrito Essais de théodicée sur la bonté de Dieu, la liberté de l'homme et l'origine du mal escrito en 1710, en el que reconoce la existencia del mal como justificación para la existencia de Dios, mostrando que el mal era necesario en un mundo de antagonismos donde cada cosa existía por la existencia de su contrario. Así, la teodicea leibniziana se entiende como "doctrina de la justificación de Dios respecto del mal en el mundo, ante el tribunal de la razón humana".
} 
un animal de la compensación. La falta de sistemas biológicos de defensa y ataque las compensa con la creación de las armas, la falta de pelaje con los abrigos y la falta de protección biológica a la intemperie la compensan con el techo, la caverna o la casa, y en ese mismo orden, la falta de instintos la compensa con las instituciones.

A través de la defensa de Dios, la teodicea leibniziana justifica la existencia del mal y del dolor en el mundo como compensación de lo bueno y lo placentero, eso significa que el sufrimiento será condición necesaria para alcanzar la felicidad (Leibniz, 2014). De tal suerte que todas las desgracias que padezca el hombre serán compensadas con situaciones y estados placenteros, pero también el sufrimiento en la tierra será compensado con un mundo ideal más allá de la vida en la tierra, será compensado con el Paraíso.

El principio de la filosofía de la historia deja al animal humano sin el mito de la creación y la protección divina. La idea de Dios como ser que hace la historia y la vida del hombre propia de la teología de la historia es desplazada por el idealismo alemán. El final de las heteronomías como orientadoras de las acciones humanas pone al hombre en el centro del mundo y le entrega el control de su existencia, su destino está en sus manos, ya no es Dios el que resuelve su vida, ahora, en sus manos está su vida, su protección y su destino. De él depende que en el mundo ocurran eventos buenos o eventos malos, mientras tanto Dios es salvado de la responsabilidad por lo que le pueda suceder al hombre (Shearn, 2013). Dios ya no es culpable de lo que le ocurra al hombre, el único culpable será el hombre mismo.

Por cuenta del idealismo, el tercero sagrado es llevado a juicio y declarado culpable de las desgracias humanas. El juicio de culpabilidad contra Dios por haber permitido la desgracia de Lisboa en 1755, cuando pudo haberla evitado, le da la libertad al hombre y lo saca de la heteronomía de Dios para dejarlo con todas las posibilidades materiales de superar su estado de minoría, y de alcanzar el mejor de los mundos posibles.

Acusado y juzgado por el desastre de Lisboa bajo los cargos de algo similar a una "omisión de socorro" por permitir la desgracia siendo bondadoso y todopoderoso, Dios es sustituido por el hombre. Desde el momento en que el hombre toma el lugar de Dios y se hace libre, también se hace responsable de todas sus acciones, incluso de sus propias desgracias.

Así, la filosofía del siglo XVIII da un giro a la teodicea, ocupa el lugar del Dios juzgado por el tribunal del hombre, y convierte a este en el creador de sí mismo, del mundo y de su propia historia (Poulain, 2003), se emancipa de su Dios y se hace dueño de las cosas del mundo, de su destino, de su progreso y de su fracaso. Fracaso que finalmente lo llevará a lo que Marquard llama la supertribunalización de lo humano: el hombre en el banquillo de los acusados, el mismo en el que un día llevó y condenó a su Dios (p. 151).

Muerto Dios, la única teodicea que puede tener éxito es la teodicea humana, y el hombre será el creador del mejor de los mundos posibles, el responsable de mejorar lo que 
ya existe y el responsable de hacer posible la vida de los hombres en mejores condiciones y con mejores prebendas, y en sustitución de Dios será el supremo ser sobre la tierra.

El hombre queda con la absoluta potestad de ser el creador de todas las cosas, de todo el mundo; por lo menos esa es la propuesta de la filosofía de la historia, aun cuando los límites de esa capacidad creadora están dentro de las fronteras de lo que Gehlen (1987) llama el segundo mundo natural del hombre: la cultura. Solo el hombre es capaz de crear el mundo que le fue negado naturalmente por sus indigencias biológicas, el mundo de la cultura, de la creación y de la transformación de las cosas de la naturaleza para crear su propio espacio vital, sin el cual estará condenado a la extinción, sentencia Gehlen.

La autonomía y la libertad de la que se hace dueño el hombre tras el juicio de Dios producen un giro hacia la nueva teodicea (Marquard, 2007), que esta vez va por la salvación de Dios y el juicio de los hombres contra el propio hombre. Ahora la defensa de Dios se basa en señalar al hombre como el único responsable de la existencia del mal y de las desgracias humanas, para acusar por los males generados. Así, solo los hombres libres son responsables por sus acciones y solo ellos van a juicio, solo ellos son condenados (Marquard, 2007, p. 76).

Así, el mal del hombre es compensado por la acusación, el juicio y la condena a la que es sometido el propio hombre; esta vez el mal no será compensado con bien como en la teodicea leibniziana, sino que la compensación del mal se hará con otro mal; así, el mal del hombre será compensado con el castigo que se estable a través de las normas de derecho. Así, el derecho va a surgir como compensación del mal.

Las instituciones jurídicas asumen la función compensatoria del mal, la desgracia que un hombre produce en otro es compensada por el actuar de las instituciones con una acción maligna contra el responsable de la desgracia, y así la compensación funciona, no en sentido inverso, mal por bien, sino en la misma línea, mal por mal.

Las normas de derecho tendrán una orientación retributiva contra el causante del mal. Cada desgracia y cada daño que se produzca con ocasión de la acción maligna tendrá una compensación vengativa; pero la venganza no será suficiente, porque el daño tendrá que ser reparado. La norma jurídica asumirá, entonces, una doble función compensatoria frente al mal; además de retribuir el mal ocasionado, procura la reparación del daño mediante el establecimiento de la indemnización, algo así como una compensación del mal por el bien de la reparación.

El derecho toma el lugar como suprema sacralidad que estaba vacante con el final de Dios, y asume el papel de mediador entre el hombre y su culpa; por tanto, el hombre queda sometido al hombre con la mediación de un tercero sagrado encarnado en la institución jurídica, que ahora tendrá el poder para determinar las culpas, direccionar la acusación y el juicio y cuantificar el mal que tiene que sufrir el culpable. 
De la culpa fluye una obligación jurídica del agente causante del daño ante el agente pasivo de la acción que el derecho logra garantizar por el uso de la fuerza, y que alcanza dos formas compensatorias del mal; una, el contragoce que produce en el afectado el dolor que sufre el agente maligno (Nietzsche, 1994), y la otra, la cuantificación material del daño sufrido y la obligación que tiene el culpable de asumir esa carga. Desde esta óptica, Nietzsche considera que el sufrimiento tiene una compensación morbosa en el deseo de venganza, de provocar el mismo mal padecido a quien lo produjo (p. 75).

Ya con el derecho entronizado, las relaciones con otros pasan por el filtro de las instituciones, por el filtro de la norma de derecho o por el filtro de las normas morales; el hombre no se regula por sí mismo, ni siquiera por la conciencia moral kantiana; se sujeta a las disposiciones que le vienen dadas por el derecho a través de las instituciones, su libertad lo convierte en un sujeto de derecho, en alguien que carga con la presunción de culpa, con la presunción de responsabilidad, y por ello tendrá que quedar bajo la racionalidad de un marco general de acción. Su libertad queda atrapada dentro de las fronteras de la culpa y la responsabilidad, y orientada por un limitado abanico de posibilidades de acción.

La sujeción al derecho se compensa, entonces, con el otorgamiento de igualdades políticas, las restricciones de acción se compensan con los derechos del hombre y luego con los derechos humanos, de nuevo el hombre recupera el lugar del todopoderoso que le había entregado al derecho y asume su papel de soberano. Toma nuevamente las riendas de su vida y se hace responsable de su propio mundo.

Ahora bajo esta lógica se explicará por qué la democracia representativa constituye la teodicea del capitalismo liberal. Para ello, tomaré como referencia la teoría de la compensación de Marquard, para sustentar la tesis según la cual el hombre mantiene una necesidad de equilibrar con el mundo abstracto de las instituciones las carencias que le vienen de su condición inacabada biológicamente. Recordemos que el hombre compensa la falta de instintos con la construcción imaginaria de las instituciones (Gehlen, 1993).

La democracia representativa comporta una forma especial en la que los agentes sociales se ven identificados con el juicio de otros en relación con el estado de cosas en el mundo, pero no hacen un juicio común de las cosas comunes, sino que terminan por sujetarse a un juicio particular que intenta de cierta forma lograr niveles de universalización por fuera del juicio de los destinatarios, por fuera del juicio de sus representados.

Es un asunto interesante, en la medida en que ahora el hombre ha transferido su juicio y su poder de decisión a otros; ¿̇a quiénes? A los que considera que pueden decidir por él y pueden juzgar por él, pero no es precisamente la figura del Dios que ya había juzgado, es la figura del hombre que todo lo puede. No habrá mejor oportunidad para que unos pocos puedan juzgar por todos, para que el juicio de las minorías sea universalizable y alcance el umbral de palabra sagrada. 
El hombre puso su facultad de juzgar en manos ajenas. Al renunciar a la capacidad de hacer valer sus dictámenes en relación con el mundo, y a la posibilidad de construir esos dictámenes en común, pierde la posibilidad de orientar su propia vida, la misma posibilidad que adquirió cuando asume su libertad tras la muerte del Dios leibniziano. Ahora es el hombre quien define la vida de otros.

La idea de libertad echa raíces en el idealismo alemán, y afianza con Schelling la premisa de que el hombre mismo es quien hace y dirige al mundo, y que en absoluto Dios interviene en ello. Sin embargo, la idea de un hombre omnipotente se somete a duras objeciones por parte de los críticos del idealismo, quienes afirman que la tesis idealista de la autonomía condena al hombre a la soledad al negar su relación con otro, y en especial al negar su condición de ser finito y atizar una rebelión contra Dios basada en el desprecio de la condición de criatura del ser humano y del mundo.

La sugerencia que hacen los críticos del idealismo para revisar la idea de autonomía pone en cuestión el papel del hombre en el control de sus propios asuntos sociales, y de paso comienza a dar forma a la necesidad de pasar por el filtro de terceros las decisiones que tengan que ver con el desarrollo de sus planes de vida y de acción, para el cumplimiento de la promesa de forjar el mejor de los mundos posibles. Ahora, la autonomía del hombre se mantendrá de manera moderada, y las decisiones de gran importancia ya no pasarán por el tamiz de sus juicios. De hecho, la idea del funcionamiento del mundo a partir de antinomias no será suficiente para salvar al hombre como sí sirvió para salvar de responsabilidad a Dios por la existencia del mal.

Ahora el reto está en definir cómo el hombre mantiene el control del mundo sin la intervención de la teología, sin la idea de Dios como gobernante, manteniendo la idea de libertad, pero sin autonomía plena; precisamente, cuando la historia le ha "pasado factura” por la incapacidad de resolver los males del mundo, y cuando su autonomía no le ha permitido resolver las insatisfacciones con el mundo, pulula el hombre insatisfecho.

Así, el hombre se encuentra ahora con una confrontación con él mismo, siendo obligado a responder por las desgracias insuperadas. La búsqueda de responsables conduce, igualmente, a la búsqueda del enemigo, del causante de los peligros y de las insatisfacciones humanas. En ese sentido,

\footnotetext{
la imputación de Dios es reemplazada por la imputación de adversarios; el temor del Señor es reemplazado por el miedo al enemigo; las buenas obras son reemplazadas por las malas palabras; la ley heterónoma de Dios es reemplazada por la ley heterónoma de la obligación de luchar. (Marquard, 2007, p. 89)
}

Lo cierto es que la autonomía del hombre queda atrapada en la paradoja de la heteronomía de la ley humana, el riesgo que produce la latencia de un enemigo que 
pone en peligro la libertad misma y el interés de los hombres por encontrar un mundo satisfactorio y placentero es el motivo perfecto para reemplazar al hombre por otro, un otro que encarne la esperanza de salvación y la autonomía que tendrá que transferírsele para que pueda defendernos de los "enemigos".

Esto supone una asimetría desde el punto de vista de la ejecución, no todos los seres humanos tienen capacidad de hacer lo que autónomamente les corresponde, y las funciones en materia de resolución de asuntos sociales están distribuidas de manera asimétrica, porque no todos los individuos pueden participar a la hora de decidir sobre los asuntos sociales; la desigualdad le da fundamento a otra idea de equilibrio, a otra idea de igualdad.

No todos pueden participar en la toma de decisiones para la construcción del mejor de los mundos posibles, y para ello serán elegidos solo unos cuantos; sin embargo, aunque no todos pueden participar en la toma de decisiones importantes para la vida social, todos sí podrán participar en la designación de los pocos que tendrán que asumir esa tarea.

De la misma forma, la exclusión en la toma de decisiones se compensa con la idea de la transferencia de decisiones; es decir, con la creencia de que las decisiones que adoptan los representantes elegidos son igualmente decisiones de sus electores, porque actúan en nombre de estos.

La noción de representación vendrá a compensar la pérdida de participación directa en la toma de decisiones, y en ese caso quienes resulten designados en un proceso de elección como representantes de un grupo de individuos serán quienes en su nombre realicen las acciones propias; los elegidos serán los encargados de hacer el mejor de los mundos posibles en nombre de los demás, los encargados de hacer posible las satisfacciones humanas, que no serán más que las satisfacciones propias de quienes tienen en sus manos la representación de los otros en el espacio político burocrático.

La idea de compensación supone una idea de necesidad y de equilibrio, y la democracia representativa responde, por un lado, a la necesidad de un ser carencial que por vivir en colectividad está necesitado de resolver múltiples situaciones que surgen de las condiciones especiales que afloran en la vida social; y por otro lado, está el problema de mantener al hombre como responsable del control del mundo sin los riesgos que implica un nivel alto de autonomía y libertad. Esto último será lo primero que se resuelva.

Las libertades y la autonomía quedarán definidas dentro de las fronteras demarcadas desde la Ilustración con la Declaración de los Derechos del Hombre y del Ciudadano, hasta la Declaración Universal de los Derechos Humanos. Ambos, como compensación por la pérdida de la autonomía plena, funcionan como instituciones que reconocen espacios de acción a los individuos para que puedan desarrollar su proyecto individual de mundo, pero en el plano público sus facultades quedan transferidas a instancias que actúan en su nombre, a la democracia, a la idea de participación política. 
Es claro que la democracia representativa se sirve del reconocimiento de las desigualdades, del final de las pluralidades y la reafirmación de las multiculturalidades, de la confirmación del individualismo, cuando todo esto fue forjado y asegurado para servir al proyecto liberal económico, todo en procura de hacerse con el control de unos aparatos políticos sin la respuesta ni la reacción de los agentes sociales, que, aislados, divididos y expropiados voluntariamente del ejercicio de su facultad de juzgar, quedan sujetos a la heteronomía de un proyecto económico y político.

El proyecto del liberalismo político apunta, precisamente, a servirse de la democracia representativa como idea de libertad para encubrir el verdadero proyecto de retornar a la teodicea leibniziana, mediante un proceso de recambio en el que se reconfigura la forma divina de Dios por la figura sagrada de un modelo político de representación que habla y juzga en nombre de todos.

Eso le permite a quienes tienen la propiedad de grandes capitales corporativos hacerse a un modelo político abierto, en el que las libertades individuales (en términos nominales) concentren la atención de los agentes sociales en sus intereses particulares bajo la idea de autonomía y soberanía, para desconectar los intereses políticos comunes de la discusión común de los agentes sociales.

El modelo de democracia representativa no sirve exclusivamente a "nobles causas" políticas, gracias a él, fascismo y nazismo ascendieron al poder en la Europa del primer tercio del siglo XX, logrando un amplio apoyo y respaldo popular para que sus máximos representantes asumieran el control político. Ahí, la democracia representativa funcionó como un medio perfecto para un ascenso límpido al poder de agentes que legitimaron sus crímenes con la alienación de los gobernados.

La misma expresión de voluntad popular que puso a Mussolini y a Hitler en la cima del poder político ahora pone a los dueños del capital corporativo, o a sus representantes, en las más altas esferas burocráticas para el control de la política instituyendo lo que Wolin (2008) llama "totalitarismo invertido".

La democracia no es un espacio deliberativo donde prime el juicio y la reflexión de los agentes sociales en torno a los asuntos fundamentales de la vida social, donde el debate de las masas fundamenta la toma de decisiones políticas, más bien resulta ser el espacio propicio para una ciudadanía pasiva, una ciudadanía que reproduce la incapacidad de respuesta igual que lo hizo con las dictaduras antes citadas, donde actuaban como "una masa políticamente desencantada y alienada cuyo apoyo era útil para conferirle legitimidad a la dictadura y ampliar su control sobre la población” (Wolin, 2008, p. 92).

Esa variante de "totalitarismo invertido" que deviene una forma de democracia representativa controlada y sostenida por el capital corporativo funciona a la inversa del totalitarismo clásico; en él la economía ya no está subordinada a la política, es la política la que está subalterna a la economía, y eso le permite desplegar toda una serie 
de decisiones que afectan la distribución de los fondos oficiales con destino a ciertos sectores sociales (p. 98).

En la práctica, los grupos económicos se apropian de los procedimientos democráticos invirtiendo cantidades importantes de recursos financieros como si se tratara de operaciones en bolsa, procurando ocupar puntos estratégicos en los espacios burocráticos que les permitan asumir la representación de los capitales en la agenda política, con un alto costo para los agentes sociales (p. 99); primero, porque los individuos son desplazados en forma efectiva de las posibilidades de ascenso político en la esfera burocrática del Estado, y segundo, porque se corta el nexo natural con los órganos legislativos que están llamados a representar al pueblo.

Como efecto del control que ejerce la economía sobre la política, la democracia se encuentra en un proceso de licuación que disuelve la masa sólida de ciudadanos y la saca del bloque burocrático para dejar que la economía asuma la orientación de las políticas en los órdenes más rentables de la burocracia más allá de la voluntad colectiva. "Así el liberalismo ha concebido como intranscendente, y por tanto peligrosa, la expansión del universo político, prefiriendo un Estado de magnates a procedimientos garantizados y garantizantes" (Cerroni, 1995, p. 215). De hecho, nociones como gobernabilidad y gobernanza sirven para legitimar en la práctica el control de los espacios institucionales del Estado por parte del poder corporativo.

El sufragio y la opinión sin efectos vinculantes se constituyen en formas de participación democrática, mientras desaparecen los controles y contrapesos democráticos para que las instituciones públicas sirvan al interés general y no al interés económico particular (Stiglitz, 2002, p. 56).

En tanto que el totalitarismo clásico impulsaba la formación de seguidores más que de ciudadanos, el totalitarismo invertido apunta en una dirección similar, porque su propósito no es el de formar ciudadanos, sino de sustituirlos por figuras como "la soberanía de los consumidores" y la "democracia de los accionistas", que dan una sensación de participación sin exigencias ni responsabilidades. Un régimen invertido prefiere tener una ciudadanía que sea cómplice sin sentido crítico más que comprometido (Wolin, 2008, p. 107).

Ideas como la dignidad humana, la autonomía y la libertad como ejes del sentido democrático devienen imposibles para la mayoría que no tiene acceso al capital económico, pues la idea de igualdad solo funciona en el plano jurídico y político, mas no así en el sentido social y real, espacio en el cual esa noción se fundamenta en la desigualdad y la diferencia, para darle sentido a la idea diferenciada de igualdad entre iguales.

Las libertades como capacidades de hacer solo son posibles en la medida en que el individuo tenga recursos para poder hacer con libertad. La tenencia de recursos económicos garantiza la realidad de las libertades nominales, y hace posible la autonomía y 
la dignidad de los sujetos (Tugendhat, 1998, p. 252); basta pensar en las condiciones de indigencia de un individuo habitante de la calle o de un individuo en condiciones de pobreza extrema para evidenciar que este sujeto no tiene la más mínima posibilidad de hacer realidad el derecho al libre desarrollo personal. La pobreza y la indigencia niegan toda posibilidad del desarrollo del individuo.

De tal manera que "los derechos tienen que ser derechos no solo de protección sino de posibilidad de realizar la autonomía... [y] La autonomía es puesta en peligro no solo por interferencia sino también por falta de condiciones favorables (Tugendhat, 1998, p. 252), de ahí que se debe garantizar el acceso a los recursos económicos como un derecho fundamental de los individuos para que sea una realidad obrar libremente.

Lo que abre las puertas del control efectivo de las instancias político-burocráticas es la capacidad de libertad que confiere la potencia económica para hacer todo cuanto sea posible en el marco de un ideal ético, si es que su ideal está dentro de un marco ético. Por consiguiente, esta noción de libertad efectiva reafirma la diferencia y la desigualdad real entre quienes pueden actuar libremente y quienes se sujetan a opciones de acción.

Así las cosas, la carencia económica se va a compensar con más derechos. Ese aumento de los derechos es directamente proporcional al aumento de la pobreza, lo cual significa que, a mayor nivel de pobreza, mayor extensión de derechos como compensación de la imposibilidad de acceso a la riqueza. La distribución de la riqueza no se produce respecto del capital económico, sino financiando servicios públicos básicos como posibilidades de acceso a los derechos conferidos. En consecuencia, la "redistribución moderna está construida alrededor de una lógica de derechos y de un principio de igualdad de acceso a cierto número de bienes fundamentales" (Piketty, 2013, p. 766).

Es esa la perspectiva política que reafirma la necesidad de diferenciar al sujeto político y al sujeto sin política. La humanidad es un concepto que está por fuera de la política (Schmitt, 2009), por tanto, a todo aquello que se suponga humano no le corresponde el carácter de sujeto político y menos puede tener estatus político.

Es claro que la orientación del concepto tiene dos intenciones muy concretas: 1) deslegitimar la potencia del individuo para levantarse contra lo establecido, ya que estaría actuando contra la humanidad; y 2) despojar de la condición política a todo individuo cuyas acciones atenten contra lo establecido o instituido.

Es la ley y no los individuos la que legitima las miradas y las formas de exclusión que se proponen en los discursos que formulan los que controlan la política y la economía:

En tal caso el "imperio del derecho" no significa otra cosa que la legitimación de un deter-

minado statu quo en cuyo mantenimiento están lógicamente interesados todos aquellos cuyo poder político o ventaja económica poseen su estabilidad en el seno de ese derecho.

(Schmitt, 2009, p. 95) 
Como el liberalismo económico no libera el acceso al capital para hacer realidad las libertades de acción, le "presta" la palabra a los individuos en forma limitada, para que puedan deliberar sobre algunos asuntos de la vida pública, pero no pueden deliberar sobre asuntos de economía y orden público. Basta con ver en el caso colombiano que los mecanismos de participación ciudadana tienen temas vedados, entre ellos, los asuntos relacionados con la economía, los impuestos, las políticas de internacionalización económica y globalización.

Reconociendo en ellos su capacidad deliberativa como sujetos capaces de lenguaje y de acción (Habermas, 1998), se retorna a la idea de igualdad política, esta vez, desde el uso discursivo. Pero el regalo viene envenenado. La libertad deliberativa habermasiana no hace más que reafirmar la idea de libertad como desigualdad (Von Uexküll, 1957), en el entendido de que solo la libertad le permite al hombre expresar su desigualdad (Habermas, 1998, p. 112).

La noción de democracia deliberativa fundada en el ejercicio comunicativo de sujetos capaces de lenguaje y acción toma al lenguaje como instrumento político para compensar la imposibilidad física de hacer realidad los derechos que requieren necesariamente capacidad económica del agente social. Eso baja la tensión entre libertades políticas y libertades individuales. Podría considerarse que es una idea de democracia económica a muy bajo costo; solo se necesita activar las posibilidades discursivas que tienen los agentes sociales para ponerse de acuerdo sobre lo que ya está acordado en el consenso.

La realidad es que la deliberación en el mundo político y social se vuelve en un intento fallido por reconocer discursivamente al agente político. La validez de los discursos no se resuelve en el plano de las razones que exponen los agentes discursivos; la validez es definida por las instancias que controlan el consenso de los discursos en los aparatos políticos transnacionales. De hecho, las prácticas que ejercen grupos de resistencia política son conceptualizadas en esas instancias, y fluye la razón discursiva de esos organismos, que, en últimas, categorizan de lícitas o ilícitas esas prácticas.

Sin embargo, el teórico de la acción comunicativa reconoce que la legitimidad de las decisiones y de las normas solo se puede alcanzar siempre que los afectados se pronuncien con un asentimiento o con una negativa sobre la decisión que se pone en juego en el mundo social (Habermas, 1991, p. 101), a pesar de que en la práctica se impongan las razones burocráticas, y poco o nada importa el asentimiento o rechazo de los afectados por la decisión.

La cuestión fundamental de esta perspectiva procedimental de la deliberación en términos democráticos es determinar qué tipo de asuntos son los que pasarán por el juicio de los agentes sociales para que nieguen o asientan sobre aquellos, o dicho en una mejor forma, no todos los asuntos se someterán a la deliberación; las grandes decisiones que atañen a los asuntos medulares de la economía, del derecho procedimental contra 


\section{Juan Carlos Quintero Calvache}

los Estados y de la política pública de los Estados seguirán discutiéndose a instancias institucionales que aseguren el consenso, el mismo que servirá para juzgar en nombre de la mayoría las mejores razones posibles.

El asunto está en que, cuando normas y decisiones gubernamentales alcanzan su legitimidad por cuenta de la razón habermasiana del mejor de los argumentos posibles, esas normas y esas decisiones deben dar cuenta de las necesidades comunes y de la aceptación de ellas por parte de los agentes sociales en el mundo real, y no sustentar la razón legitimadora en los límites de un argumento considerado como "el mejor" de todos los argumentos posibles (Poulain, 1998, p. 32).

Es evidente que los juicios políticos anticipados por el consenso institucional son causantes de algunas enfermedades formales de la democracia. Los niveles de abstencionismo dan cuenta del malestar que se vive en la democracia orientada por "representantes populares" que responden a intereses y necesidades particulares, y pone en crisis el llamado procedimentalismo democrático de las élites postulado por Bobbio (1999), porque las mayorías, que participan y aportan en la asunción de las élites al poder político, notan cómo la representación de los espacios políticos es ocupada por agentes que interpretan los intereses de una sociedad económicamente fuerte y establecen normas e instituciones que no interpretan los intereses y las necesidades de la mayoría.

Sin embargo, el proceso comunicativo de los agentes sociales como un instrumento legitimador para juzgar argumentadamente el orden político queda sujeto a las justificaciones inmersas en el orden jurídico, que oponen sus razones, normalizadas y legalizadas por el proceso legislativo, a las razones que fluyen de la comunicación de los agentes sociales.

Lo que interesa a la democracia es el papel que desempeña la mayoría en el juego de las designaciones, pero excluye de la discusión las desigualdades que en términos socialmente reales median la relación entre electores y elegidos. De ahí que las necesidades y los deseos de los individuos queden atados a una racionalidad que define anticipadamente sus orientaciones y sus metas, para hacer del proyecto democrático la única necesidad y el único deseo posible de los agentes sociales en un mundo de la vida previamente establecido. Un mundo en el que la democracia representativa define los intereses, las necesidades y los deseos de los individuos, a la vez que realiza los juicios que tienen que utilizar los agentes sociales como "argumentos razonables" para juzgar el contexto social y político en el que se desarrollan sus vidas.

La noción de poder burocrático en Weber expone claramente los matices de la democracia contemporánea, porque evidencia que el modelo no está concebido para orientar formas adecuadas de buen gobierno, sino como instrumento para seleccionar una clase dirigente determinada, no abierta, que responda a orientaciones específicas que dejen de lado lo que se conocía como el arte del buen gobernar. Así, a la manera 
de Bobbio y de Sartori, la democracia es un conjunto de reglas mínimas que funcionan para instalar a una élite en el poder.

Por eso, para los teóricos de la democracia, esta teoría aplicada alberga en su interior su propio enemigo, porque no responde a los principios que ella misma pregona, y deja en manos de unos pocos lo que les pertenece a muchos. El verdadero peligro que amenaza a una democracia que oficialmente ya no tiene enemigos no está en la competencia de contraideales, sino en reclamar una "verdadera democracia" que trasciende y repudia la que hay.

El presupuesto y la condición necesaria para ese desarrollo es que, para pasar de la democracia electoral basada en la opinión pública a una democracia donde el demos decide por sí mismo cada una de las cuestiones, "haría falta un nuevo demos, un pueblo que esté verdaderamente informado y sea verdaderamente competente. $\mathrm{Si}$ no, el sistema se vuelve suicida. Si confiamos a unos analfabetos (políticos) el poder de decidir sobre cuestiones de las que no sabe nada, entonces ipobre democracia y pobres nosotros!" (Sartori, 2009, p. 40).

De hecho, no hay sujetos soberanos, comunidades que respondan a su propia racionalidad, a la racionalidad que deviene sus propias dinámicas, la realidad de sus propias necesidades e intereses, porque el hombre libre que pregonaba la Ilustración, y que se reafirmó con la llamada Aufklärung kantiana, no es más que una garantía para la obediencia a una racionalidad universal (Foucault, 1994, p. 436).

La teoría del consenso que hoy por hoy pregonan los seguidores del habermasianismo no es más que una réplica del obedecimiento a la razón universal que se viene pregonando desde la Ilustración, que entraña en sí misma una orientación dogmática de reconocer un interés y una necesidad única para todos, y convirtiendo las necesidades fuera de esa unicidad en enfermedades del agente social.

La razón universal implica en el agente social la obligación de mantenerse dentro de los límites por ella definidos, solo con la posibilidad de juzgar sus propias necesidades y de reclamar participación en el espacio político haciendo uso de los criterios previamente establecidos, reproduciendo los discursos que han definido por anticipado las formas de pensar y de enjuiciar las situaciones del mundo, sin transgredir la palabra sagrada.

La apuesta que hace el capitalismo a través del modelo democrático es la de lograr que los agentes sociales se reconozcan en lo que está dado, en el mundo que está anticipadamente determinado para todos, y se identifiquen en los juicios anticipados que definen las relaciones sociales, sin que ello tenga que pasar por un juicio de reconocimiento individual por fuera de los marcos delimitados para reconocer el mundo.

La promesa del capitalismo avanzado se centra ahora en la noción pragmática de la política, en la libertad que adquieren los individuos para hacerse con el logro de sus deseos como efecto de sus acciones, sin desbordar los límites de los deseos que están ya definidos por anticipado en el consenso. Un consenso que establece un acuerdo 
presuntamente común en torno a las necesidades y las normas que presume ser aceptado por todos los agentes sociales sin juicio alguno (Poulain, 1991, p. 132).

El encierro que trae la creencia en el consenso, a la vez que reduce las posibilidades de oposición, pone en cuestión las observaciones que se formulan alrededor de una razón que está anticipada en un consenso que se supone es la razón universal aceptada por todos los miembros de la colectividad.

El problema que plantea esta noción de la razón consensuada está en el interior de la razón devenida por las normas internacionales de una comunidad internacional que ahora está juzgando la justicia de los pueblos, y fundado en el discurso de la defensa de los derechos humanos, impide que los pueblos, incluso los propios pueblos que son víctimas de la barbarie, decidan autónomamente qué hacer con sus victimarios cuando se acuerda el final de las hostilidades.

Las mismas agencias internacionales de defensa de los derechos humanos se han arrogado ahora el derecho de sustituir a los agentes sociales para pensar y juzgar en su nombre, decidiendo por encima de ellos los temas que se tienen que someter a debate judicial, como si se tratara de una conciencia moral para el colectivo que toma decisiones en nombre de la mayoría, sustituyendo la facultad instituyente de los colectivos para decidir qué hacer con sus vidas, por una imagen sagrada que se arroga el derecho de hablar y juzgar en nombre de todos.

Lo que deberían hacer las agencias defensoras de los derechos humanos para anteponer los derechos humanos a los intereses de las corporaciones y agencias transnacionales es llamar a los principales actores capitalistas para que rindan cuentas por su responsabilidad en la violación masiva de los derechos humanos devenida por el aumento de la miseria en pueblos sin condiciones de desarrollo (De Sousa Santos, 2010, p. 89).

Si realmente se está en un modelo democrático, lo que menos deben perder los individuos es la palabra, la posibilidad de pronunciarse en torno a lo que sucede en su mundo, de decidir las cosas de su mundo, y de intervenir en la solución a los problemas que afronta su mundo. Pero, en realidad, lo que hace la democracia y los agentes transnacionales que gravitan en ella es arrebatarles la palabra a los agentes sociales, la cual solo se les puede otorgar como instrumento para subvertir los modelos políticos incompatibles con el capitalismo privado.

El hombre comprende lo que se le pone de presente siempre que eso esté mediado por los juicios de terceros que le dicen cómo debe comprender lo que está frente a él, y cómo debe integrarse en el mundo que se le pone de presente, más allá de cualquier necesidad particular que haya sido considerada autónomamente por él. En el mundo de la democracia, los consensos ni siquiera identifican, sino que definen las necesidades de los agentes sociales en un contexto político específico. 
Después de todo, es posible seguir pensando en una noción de democracia discursiva y deliberativa, cuando la palabra y el juicio le vienen al individuo por cuenta de terceros institucionales que hablan y juzgan en su nombre; cuando la palabra se le otorga al individuo por cuenta de la representación y, al mismo tiempo, se le niega la palabra que es producto de sus propios juicios que juzgan el mundo al margen de las líneas de pensamiento y de discurso que determinan cómo deben juzgan los individuos. De ahí que "el término 'democracia' es, hoy, el organizador principal del consenso, en el que se pretende reunir bajo esa palabra tanto el derrumbe de los Estados socialistas, como el supuesto bienestar de nuestros países, o las cruzadas humanitarias de Occidente" (Badiou, 1999, p. 1).

No hay que perder de vista que el liberalismo se mueve entre la ética y la economía (Schmitt, 2009), entre el discurso del tener que ser y el poder tener, todos apoyados por un derecho que regula las relaciones entre Estado e individuo, y que por medio de este se garantizan derechos al desarrollo de la individualidad para asegurar la propiedad privada como centro de los polos de la ética y la economía (Schmitt, 2009, p. 99).

Así, aislando el juicio objetivador del mundo que producen los individuos, del juicio institucional-burocrático que juzga anticipadamente los asuntos comunes, se neutralizan los diálogos intersubjetivos y se afirman las nociones universales que rigen el mundo social, y se niega cualquier otra noción que pretenda poner en cuestión lo instituido.

No es posible que los universales del liberalismo entren en una dialéctica con nociones que sustituyan la individualidad en lo político, como oponiendo la noción de acumulación con la de distribución equitativa. Un planteamiento en ese sentido no tardará en ser catalogado enemigo de lo instituido, para oponerle universales éticos que lo hagan "enemigo de todos". Por tanto, los derechos humanos vienen a constituirse en la teodicea de la democracia, que salva al hombre de la propia desagracia que se produce en el interior del modelo político.

\section{Resultados}

La sustitución de la facultad de juzgar por el consenso anticipado sobre lo que debe juzgarse cosifica y transgrede la condición humana y reduce al individuo al nivel de un aparato instintivo que está obligado a responder a las "propiedades mágicas" del lenguaje. De ahí que el individuo en el modelo de democracia representativa solo puede disponer de la palabra para reproducir los discursos que han juzgado anticipadamente las situaciones del mundo que ha sido determinado y juzgado en su nombre.

En la era de la democracia del capitalismo privado todo tiene su precio. Así como en el Leviatán hobbesiano la protección compensa la pérdida de la libertad absoluta, en el modelo democrático capitalista los derechos y las libertades compensan la pérdida de las libertades absolutas del juicio. La democracia y los derechos humanos cumplen una función instrumental en favor del capitalismo privado, en cuanto funcionan como 
aparatos de compensación, encargados de realizar un juicio común de los asuntos del mundo social y político, que están inmersos en la era de la mundialización.

La desaparición de las libertades absolutas del juicio supone una sustitución conceptual de la justicia respecto de la disposición de la palabra y de la valoración de las situaciones del mundo. De hecho, la sustitución de las libertades absolutas de juicio garantiza que en las sociedades actuales se establezcan nuevas categorías universales que van a favorecer los alcances de un capitalismo cada vez más acaparador, interesado más en el ascenso de lo insignificante que en el reconocimiento de las libertades valorativas de los individuos,

y esto supone a la larga, una amenaza para la supervivencia del mismo sistema. Cuando se proclama abiertamente, como ocurre en todas las sociedades occidentales, que el único valor es el dinero, el beneficio, que el ideal sublime de la vida social es enriqueceos (y en Francia es a los socialistas a quienes ha de reconocérseles el mérito de haberlo proclamado como la derecha no había osado hacerlo) ¿̇puede una sociedad seguir funcionando y reproduciéndose sobre ésta única base? (Castoriadis, 1996a, p. 91)

Mientras la construcción de los individuos está ligada a mecanismos y técnicas, el sujeto político no es un sujeto liberado, en cuanto sus posibilidades de acción están atadas a las acciones que están preconcebidas para él, y en ellas están vinculadas las acciones discursivas. Por eso, las libertades del juicio crítico deben estar ligadas al proceso de subjetivación del individuo para que este pueda construirse a partir de su propia libertad y de su propio gobierno como un agente que se autoelabora a partir de actos que están por ser elaborados (Foucault, 1982, p. 275), y no a partir de actos que están anticipadamente constituidos.

La búsqueda por una sociedad autónoma se hace difícil cuando la facultad de juzgar el mundo queda sujeta a orientaciones racionalizadas que terminan por socavar la dignidad humana (González, 2016, p. 393) haciendo inalcanzable el reto de lograr, por lo menos, una democracia del juicio.

\section{Referencias}

Avritzer, L. y Sousa Santos, B. de (3 noviembre 2003). Para ampliar el canon democrático. En EUROZINE. Recuperado de http://www.eurozine.com/ para-ampliar-el-canon-democratico/

Badiou, A. (1999). Dos ensayos de metapolítica. Acontecimiento, 17, 1-9.

Bolk, L. (2007). El hombre problema: retardación y neotenia. Cali, Colombia: Universidad del Valle. 
Castoriadis, C. (1996a). El ascenso de la insignificancia. Madrid: Frónesis.

Castoriadis, C. (1996b). La crisis del capitalismo: su impacto social e individual. Recuperado de http://www.omegalfa.es/

Cerroni, U. (1995). La democracia como estado de cultura. En P. Santana (ed.), Las incertidumbres de la democracia (pp. 207-235). Bogotá: Foro Nacional por Colombia.

Foucault, M. (1982). Dichos y escritos (vol. 4). París: Gallimard.

Foucault, M. (1994). Dits et ëcrits (vol. 4). París: Gallimard.

Gehlen, A. (1987). El hombre: su naturaleza y su lugar en el mundo. Salamanca: Sígueme.

Gehlen, A. (1993). Antropología filosófica: del encuentro y descubrimiento del hombre por sí mismo. Barcelona: Paidós.

González, W. (2007). De la neotenia a la filosofía. En L. Bolk, El hombre problema: retardación y neotenia. Cali, Colombia: Universidad del Valle.

González, W. (2016). La institución instituyente frente al ascenso de lo insignificante. En J. A. Gómez Gómez (ed.), Estudios de derecho constitucional contemporáneo (pp. 381-397). Bogotá: Ibáñez.

Habermas, J. (1991). Escritos sobre moralidad y eticidad. Barcelona: Paidós.

Habermas, J. (1998). Teoría de la acción comunicativa. Madrid: Taurus.

Leibniz, G. (2014). Teodicea: ensayos sobre la bondad de Dios, la libertad del hombre y el origen del mal. Madrid: Biblioteca Nueva.

Marquard, O. (2001). Filosofía de la compensación. Barcelona: Paidós.

Marquard, O. (2007). Las dificultades con la filosofía de la historia. Valencia: Pre-textos.

Nietzsche, F. (1994). Genealogía de la moral. Madrid: Alianza Editorial.

Piketty, T. (2013). Le capital au XXIe siècle. París: Édition du seuil.

Poulain, J. (1991). L’âge pragmatique ou l'expérimentation totale. París: L'harmattan.

Poulain, J. (1993a). La loi de vérité ou la logique philosophique du jugement. París: Albin Michel.

Poulain, J. (1993b). La neutralisation du jugement ou la critique pragmatique de la raison politique. París: L'Harmattan.

Poulain, J. (1998). La condition démocratique: justice, exclusion et vérité. París: L'Harmattan.

Poulain, J. (2003). La apuesta por la verdad: crítica de la razón pragmática. Cali, Colombia: Extremo Occidente. 
Radhakrishnan y Raju, P. T. (1964). El concepto del hombre: estudio de filosofía comparada. México: Fondo de Cultura Económica.

Sartori, G. (2009). La democracia en 30 lecciones. Bogotá: Taurus.

Shearn, S. (2013). Crítica moral y la defensa de la teodicea. Estudios Religiosos, 49(4), 439-458.

Schmitt, C. (2009). El concepto de lo político. Madrid: Alianza Editorial.

Sousa Santos, B. de (2010). Descolonizar el saber, reinventar el poder. Montevideo: Trilce.

Stiglitz, J. (2002). El descontento con la globalización. En F. Giraldo (comp.), Pánico en la globalización (pp. 57-88). Bogotá: Fundación para la Investigación y la Cultura.

Tugendhat, E. (1998). Ser, verdad y acción. Barcelona: Gedisa.

Tugendhat, E. (2002). Problemas. Barcelona: Gedisa.

Uexküll, J. von (1957). Cartas biológicas a una dama. Santiago de Chile: Zig-zag.

Wolin, S. W. (2008). Democracia S. A.: la democracia dirigida y el fantasma del totalitarismo invertido. Buenos Aires: Katz. 